\title{
Reflexiones sobre el Sistema Interamericano de Protección de los Derechos Humanos a propósito de un caso contencioso relativo a la aplicación de la pena de muerte
}

\author{
Luis Alberto Huerta Guerrero*
}

\section{Presentación}

Uno de los grandes avances ocurridos a partir de la segunda mitad del siglo $\mathrm{XX}$ en materia de derechos humanos fue el progresivo desarrollo de un sistema internacional orientado a su tutela y promoción. El primer gran momento se dio con la aprobación de instrumentos declarativos por medio de los cuales se reconoció un conjunto de derechos como inherentes al ser humano. El segundo paso lo constituyó la adopción de tratados internacionales sobre derechos humanos, que contienen obligaciones jurídicas para los Estados respecto a estos derechos y cuyo incumplimiento puede dar lugar a una responsabilidad internacional. La tercera etapa ha estado constituida por el establecimiento de órganos internacionales de protección de los derechos humanos, con distinto origen (convencionales y no convencionales), con distintas funciones (promoción y protección), y cuyas decisiones tienen asimismo diferentes alcances (recomendaciones, opiniones consultivas y sentencias de cumplimiento obligatorio). Sin duda alguna, en el marco de esta tercera etapa, un lugar importante en la tutela internacional de los derechos humanos lo tienen los tribunales internacionales, que han venido desarrollando una importante jurisprudencia relacionada con el contenido de estos derechos y las obligaciones del Estado de respetarlos y garantizarlos.

El denominado «Sistema Interamericano de Protección de los Derechos Humanos" ha atravesado por estas etapas; pero, a pesar de que la Declaración Americana de los Derechos del Hombre y del Ciudadano fue aprobada en

* Profesor de la Facultad de Derecho de la Pontificia Universidad Católica del Perú. Investigador de la Comisión Andina de Juristas 
1948, de que la Comisión Interamericana de Derechos Humanos inició sus funciones en 1960, de que la Convención Americana de Derechos Humanos entró en vigencia en 1978 y de que la Corte Interamericana de Derechos Humanos inició oficialmente sus actividades en 1979, nos encontramos todavía ante un sistema que se encuentra en permanente perfeccionamiento. Por eso, resulta necesario profundizar en las instituciones y procedimientos del sistema interamericano de protección de los derechos humanos, y eso requiere un análisis de los diferentes casos que han llegado a conocimiento de la Comisión y la Corte Interamericana de Derechos Humanos.

El presente trabajo se enmarca en esta perspectiva y contiene un análisis de los casos Hilaire, Constantine y otros, y Benjamin y otros, seguidos contra el Estado de Trinidad y Tobago. Estos fueron acumulados y resueltos de manera conjunta por la Corte Interamericana de Derechos Humanos mediante sentencia del 21 de junio del 2002. La controversia central estuvo relacionada con la condena a pena de muerte impuesta a 31 personas en el Estado demandado, en aplicación de la denominada Ley de Delitos contra la Persona.

Para tal efecto, presentaremos los hechos más relevantes relacionados con estos tres casos, así como aspectos generales relacionados con su trámite ante la Comisión Interamericana de Derechos Humanos. La parte central del trabajo se relaciona con el procedimiento de estos casos ante la Corte Interamericana, por lo que en la sección correspondiente se comentan las excepciones preliminares presentadas por el Estado demandado, las medidas provisionales adoptadas a favor de las presuntas víctimas, la decisión de la Corte de acumular los tres casos y la sentencia sobre el fondo. Este último punto incluye un análisis sobre los derechos reconocidos en la Convención Americana que fueron afectados.

\section{Hechos relevantes}

Los hechos relevantes para el análisis de estos tres casos son los siguientes:

- La existencia en Trinidad y Tobago (desde 1925) de la denominada Ley de Delitos contra la Persona, que establece la pena de muerte como sanción única para el delito de homicidio intencional. El contenido de esta norma y su aplicación serán el eje central de la controversia ante la Comisión y la Corte Interamericana.

- En aplicación de la mencionada ley, 31 personas fueron juzgadas, declaradas culpables de homicidio intencional y condenadas a morir en la horca. Las fechas de las detenciones y de las sentencias finales varían de un 
caso a otro, pero en términos generales se trata de juicios iniciados y resueltos durante los años noventa.

- Todas las presuntas víctimas acudieron a los correspondientes procesos internos para la revisión de sus condenas.

- En los casos de la mayoría de las presuntas víctimas, no se respetaron las garantías del debido proceso en la fase previa al juicio, durante su desarrollo y en la etapa de apelación, en virtud de diversos factores como la demora injustificada en los procesos y la falta de asistencia letrada.

- En los casos de la mayoría de las presuntas víctimas, los plazos entre su arresto y la respectiva decisión judicial final duraron entre un mínimo de cuatro años hasta un máximo de 11 años y nueve meses.

- Al momento de la sentencia de la Corte Interamericana (21 de junio del 2002), de las 31 presuntas víctimas, 29 se encontraban detenidas en las prisiones de Trinidad y Tobago, y en espera de su ejecución en la horca, y existían dos excepciones, la de Joey Ramiah, quien fue ejecutado, y la de Wayne Matthews, cuya pena fue conmutada.

\section{Procedimiento ante la Comisión Interamericana de Derechos Humanos}

La Convención Americana de Derechos Humanos (en adelante la Convención) ha establecido un mecanismo orientado a analizar y resolver aquellas situaciones o actos contrarios a su contenido que se produzcan en la jurisdicción de los Estados parte de este tratado. El procedimiento respectivo se inicia ante la Comisión Interamericana de Derechos Humanos (en adelante $\mathrm{CIDH}$ ), ante la cual se siguen las siguientes etapas: a) el establecimiento de la competencia de la CIDH, b) la fase de admisibilidad, c) la fase contradictoria y la instrucción del procedimiento, d) la búsqueda de una solución amistosa (opcional) y e) la decisión de la CIDH. ${ }^{1}$

En el caso objeto de análisis, diversas firmas británicas de abogados presentaron 31 denuncias ante la Comisión entre julio de 1997 y mayo de 1999, referidas a diferentes personas condenadas a pena de muerte en el Estado de Trinidad y Tobago. Estas denuncias se tramitaron por medio de tres procedimientos diferentes (caso Hilaire, caso Constantine y otros, y caso Benjamin y otros), que fueron posteriormente acumulados por la Corte (véase sección IV, numeral 3).

El 21 de abril de 1999, la Comisión aprobó el informe 66/99 en el caso

FAÚNDEZ LEDESMA, Héctor. El sistema interamericano de protección de los derechos humanos (aspectos institucionales $y$ procesales), 2. ${ }^{a}$ ed. San José: IIDH, 1999, pp. 199344. 
Hilaire. Dicho informe fue transmitido al Estado el 26 de abril del mismo año. El 18 de mayo de 1999, el Estado envió a la CIDH su respuesta.

El 19 de noviembre de 1999, la Comisión aprobó el informe 128/99 en relación con los 23 casos que conformaban el caso Constantine y otros. Dicho informe fue transmitido al Estado el 22 de noviembre del mismo año. El 22 de enero de 2000, el Estado envió a la CIDH su respuesta.

El 13 de junio de 2000, la Comisión aprobó el informe 53/00 en relación con los siete casos que conformaban el caso Benjamin y otros. Dicho informe fue transmitido al Estado el 5 de julio del mismo año, pero este no envió a la Comisión respuesta alguna ni le suministró información en relación con las medidas que pudiera haber adoptado para dar cumplimiento a sus recomendaciones.

Luego de transcurridos tres meses desde la remisión de los informes de la $\mathrm{CIDH}$ al Estado demandado, los tres casos fueron presentados ante la Corte Interamericana de Derechos Humanos.

\section{Procedimiento ante la Corte Interamericana de Derechos Humanos}

En términos generales, las etapas del proceso ante la Corte Interamericana incluyen: a) el establecimiento de su competencia para conocer el caso sometido a su jurisdicción; b) la evaluación de los requisitos y condiciones de admisibilidad; c) una fase opcional de excepciones preliminares; d) una fase sobre el fondo del asunto (escrita y oral) que culmina con la sentencia de la Corte; y e) una fase de reparaciones (que puede darse junto con la sentencia o en una etapa posterior). En el marco de este proceso, pueden dictarse medidas provisionales y es asimismo posible la acumulación de procesos. ${ }^{2}$

Respecto al caso objeto de análisis, nos interesa abordar, en particular, los temas relacionados con las excepciones preliminares, las medidas provisionales y la sentencia sobre el fondo.

2 A diferencia de lo que ocurre con el procedimiento ante la $\mathrm{CIDH}$, la Convención Americana no señala mayores alcances sobre el proceso ante la Corte. Si bien el capítulo VIII (referido a la Corte) tiene una sección 3 denominada "Procedimiento", esta no establece disposición alguna sobre este tema sino sobre el fallo final. Es en el estatuto y el reglamento de la Corte en los que se encuentran las normas que regulan el proceso ante este tribunal internacional. 


\section{Excepciones preliminares}

En los procesos ante la Corte Interamericana, los Estados demandados pueden presentar excepciones preliminares a fin de objetar la competencia del tribunal para conocer el caso o la admisibilidad de la demanda. Mediante su jurisprudencia, la Corte ha ido precisando los alcances de esta etapa procesal. De acuerdo con Reina: ${ }^{3}$

La mayoría de las excepciones preliminares planteadas y consideradas por la Corte han estado relacionadas con la admisibilidad del caso ante el Tribunal y con su competencia para conocerlo. Varias de ellas aparentemente han sido interpuestas y fundamentadas sin haber analizado adecuadamente elementos importantes. La jurisprudencia del Tribunal sobre excepciones preliminares, si es estudiada cuidadosamente por los Estados y la Comisión, servirá para que no se vuelvan a presentar situaciones similares; lo que coadyuvará a que la Corte analice y resuelva sólo aquellas excepciones preliminares que tengan la fuerza suficiente para evitar que ésta resuelva el fondo del asunto.

Si bien la institución de las excepciones preliminares podría ser mal utilizada por los Estados con el fin de dilatar el desarrollo de los procesos ante la Corte -como en la práctica suele ocurrir-, no se puede negar su importancia en el marco de un proceso ante un tribunal internacional. La propia Corte ha señalado, al respecto, que le corresponde «guardar un justo equilibrio entre la protección de los derechos humanos, fin último del sistema, y la seguridad jurídica y equidad procesal que aseguran la estabilidad y confrabilidad de la tutela internacional». ${ }^{4}$

En el caso concreto, el Estado demandado presentó excepciones preliminares respecto a los tres casos sometidos ante la Corte. Estas se dirigieron a cuestionar su competencia para conocer estos casos, basados en los siguientes argumentos: a) la extemporaneidad de la presentación de la demanda y de la «aceptación" de la competencia de la Corte; y b) la falta de competencia ratione materiae.

3 Reina, Ana María. "Las excepciones preliminares en el sistema interamericano de derechos humanos". En La Corte y el Sistema Interamericano de Derechos Humanos. San José: Corte IIDH, 1994, p. 440.

4 Caso Cayara, sentencia sobre excepciones preliminares del 3 de febrero de 1993. En este proceso, la $\mathrm{CIDH}$ sometió el caso ante la Corte fuera del plazo de tres meses establecido en el artículo 51 de la Convención, motivo por el cual la Corte declaró fundada la excepción y ordenó archivar el expediente, sin perjuicio que la $\mathrm{CIDH}$ pudiera hacer uso de las facultades que le otorga el citado artículo 51 de la Convención. 
Sobre estos temas, la Corte se pronunció en las respectivas sentencias sobre excepciones preliminares, todas ellas de fecha 1 de noviembre del 2001. A continuación presentamos los argumentos más importantes respecto a estas decisiones. ${ }^{5}$

a) Extemporaneidad de la presentación de la demanda y de la «aceptación" de la competencia de la Corte

El artículo 51.1 de la Convención establece:

Si en el plazo de tres meses, a partir de la remisión a los Estados interesados del informe de la Comisión, el asunto no ha sido solucionado o sometido a la decisión de la Corte por la Comisión o por el Estado interesado, aceptando su competencia, la Comisión podrá emitir, por mayoría absoluta de votos de sus miembros, su opinión y conclusiones sobre la cuestión sometida a su consideración [subrayado nuestro].

Al respecto, el Estado demandado señaló dos cosas:

- que la CIDH presentó el caso ante la Corte más allá del plazo de «noventa días»; y

- que, dentro de ese plazo, la Corte tenía que aceptar la demanda respectiva, lo que tampoco ocurrió.

Respecto al primer tema, la Corte reiteró su jurisprudencia respecto a la manera de interpretar la expresión "tres meses" empleada en el artículo 51.1 de la Convención. Esta debe entenderse como «mes calendario gregoriano, es decir, de fecha a fecha». Así, por ejemplo, si la remisión del informe de la CIDH se produce el día 11 de junio de un año cualquiera, el plazo de tres meses se cumpliría el 11 de setiembre de ese mismo año. Por lo tanto, la Corte entendió que no había mayor problema respecto al cumplimiento del plazo de "tres meses» («noventa días" según el Estado demandado) y centró su análisis en torno a si debía "aceptar su competencia" dentro de ese plazo. Sobre esto señaló:

Lo que el artículo 51.1 determina es un plazo para la presentación de la demanda ante la Corte y no tiene relación directa con actos de la Corte relativos a la determinación de su competencia. Cuando en el texto del artículo 51.1 se dice «aceptando su competencia", éste se refiere a la aceptación de la competencia de la Corte por parte de un Estado y no a las actuaciones por parte de la Corte en ejercicio de su competencia [párrafo 40 de la sentencia, subrayado nuestro].

5 Las tres sentencias tienen un contenido similar. Salvo referencia diferente, todas las menciones que en esta sección se realicen a una sentencia de la Corte corresponden a la sentencia sobre excepciones preliminares del caso Benjamín y otros. 
Sobre la base de estos considerados, desestimó el primer argumento de la excepción preliminar.

b) Falta de competencia ratione materiae

El artículo 62 de la Convención Americana establece normas relacionadas con el reconocimiento por los Estados parte de la competencia contenciosa de la Corte (incisos 1 y 2) y la competencia ratione materiae de este tribunal (inciso 3). Al respecto señala:

1. Todo Estado parte puede, en el momento del depósito de su instrumento de ratificación o adhesión de esta Convención, o en cualquier momento posterior, declarar que reconoce como obligatoria de pleno derecho y sin convención especial, la competencia de la Corte sobre todos los casos relativos a la interpretación o aplicación de esta Convención.

2. La declaración puede ser hecha incondicionalmente, o bajo condición de reciprocidad, por un plazo determinado o para casos específicos. [...]

3. La Corte tiene competencia para conocer de cualquier caso relativo a la interpretación y aplicación de las disposiciones de esta Convención que le sea sometido, siempre que los Estados Partes en el caso hayan reconocido o reconozcan dicha competencia, ora por declaración especial, como se indica en los incisos anteriores, ora por convención especial [subrayados nuestros].

Por su parte, el artículo 75 del mismo tratado establece: «Esta Convención sólo puede ser objeto de reservas conforme a las disposiciones de la Convención de Viena sobre Derecho de los Tratados, suscrita el 23 de mayo de 1969" (subrayado nuestro).

El Estado demandado, en su instrumento de adhesión a la Convención, reconoció la competencia contenciosa de la Corte pero con la siguiente reserva:

[...] respecto al artículo $62^{\circ}$ de la Convención, el Gobierno de la República de Trinidad y Tobago, reconoce la jurisdicción obligatoria de la Corte Interamericana de Derechos Humanos que se estipula en dicho artículo sólo en la medida en que tal reconocimiento sea compatible con las secciones pertinentes de la Constitución de la República de Trinidad y Tobago, y siempre que una sentencia de la Corte no contravenga, establezca o anule derechos o deberes existentes de ciudadanos particulares [párrafo 42 de la sentencia, subrayado nuestro].

Para Trinidad y Tobago, esta reserva impedía a la Corte conocer los casos Hilaire, Constantine y otros, y Benjamín y otros. Pero incluso en el caso que se desconociesen los efectos de dicha reserva, eso no implicaría que la Corte tuviese competencia para conocer tales casos, pues la invalidez de la reserva 
llevaría a la invalidez total del reconocimiento de la competencia de la Corte por parte del Estado demandado. ${ }^{6}$

Al momento de resolver estos cuestionamientos, la Corte se pronunció sobre diferentes aspectos relacionados con la declaración de los Estados, en la que reconocen la competencia contenciosa de la Corte y las reservas a dicha declaración. A efectos de este trabajo, los presentamos en el siguiente orden:

i) Lo primero a resaltarse es que la Corte haya señalado que, en razón del citado artículo 62.3 de la Convención, tiene competencia para pronunciarse sobre la validez de las "reservas» a su competencia. En este sentido, reiteró su jurisprudencia, según la cual las declaraciones que efectúan los Estados al reconocer su competencia, de conformidad con el artículo 61.1 de la Convención, presuponen que estos han admitido «el derecho de la Corte a resolver cualquier controversia relativa a su jurisdiccións. ${ }^{7}$ Asimismo, la Corte señaló que no tiene sentido suponer que un Estado que decidió libremente su aceptación a la competencia contenciosa de este tribunal «haya pretendido en ese mismo momento evitar que ésta ejerza sus funciones según lo previsto en la Convención. Por el contrario, la sola aceptación del Estado conlleva la presunción inequivoca de que se somete a la competencia contenciosa de la Corten (párrafo 81 de la sentencia, subrayado nuestro).

ii) Un segundo tema a destacar es que la Corte se haya pronunciado sobre las características especiales que deben tomarse en cuenta para evaluar las declaraciones de los Estados al momento de reconocer su competencia. En este sentido, precisó que tales declaraciones deben ser interpretadas «de acuerdo con los cánones y la práctica del Derecho Internacional en general, y del Derecho Internacional de los Derechos Humanos en particular, y que proporcione el mayor grado de protección a los seres humanos bajo su tutela" (párrafo 70). La referencia a estos criterios es de especial importancia, pues demuestra que, para una adecuada interpretación de las normas internacionales sobre derechos humanos, existen elementos particulares que deben ser observados. En el caso concreto, esta particularidad será analizada a

6 En las sentencias sobre excepciones preliminares, se señala el siguiente argumento de Trinidad y Tobago: "Si la reserva del Estado fuere, por algún motivo, considerada inválida, no significaría que el Estado hubiese declarado, ilimitadamente, su aceptación de la competencia contenciosa de la Corte. Por el contrario, queda claro que el Estado nunca tuvo la intención de aceptar, en su totalidad, la competencia de la Corte. Si la reserva es inválida, la declaración fue inválida y el Estado no presentó nunca su declaración” (párrafo 51 de la sentencia).

7 Caso Ivcher Bronstein, sentencia sobre competencia del 24 de setiembre de 1999, párrafo 34 , y caso Tribunal Constitucional, sentencia sobre competencia del 24 de setiembre de 1999, párrafo 33. 
propósito de la relación entre las reservas permitidas a la Convención y el objeto y fin de este tratado.

iii) El tercer aspecto que nos interesa resaltar es el análisis que realiza la Corte sobre si la "reserva" planteada por Trinidad y Tobago, al reconocer su competencia contenciosa, implicaba que no podía conocer los casos Hilaire, Constantine y otros, y Benjamin y otros.

El tema de las reservas a la Convención no era nuevo para la Corte, pues había sido objeto de análisis en su opinión consultiva $02 / 82$, del 24 de setiembre de 1982, denominada "El efecto de las reservas sobre la entrada en vigencia de la Convención Americana sobre Derechos Humanos». En aquella ocasión, señaló los siguientes aspectos que resultan relevantes para este trabajo:

- Los Estados pueden efectuar reservas, de conformidad con la Convención Americana y la Convención de Viena «siempre y cuando éstas no sean incompatibles con el objeto y fin del tratado» (subrayado nuestro).

- En el caso de los tratados sobre derechos humanos, como la Convención Americana, su objeto y fin lo constituye "la protección de los derechos fundamentales de los seres humanos, independientemente de su nacionalidad, tanto frente a su propio Estado como frente a los otros Estados contratantes".

Sobre la base de estas premisas, la Corte evaluó los alcances de la reserva formulada por el Estado demandado con la finalidad de determinar si era compatible con el objeto y fin de la Convención. Sus principales argumentos fueron:

- El instrumento de aceptación, por parte de Trinidad y Tobago, de la competencia contenciosa del Tribunal, no era conforme al contenido del artículo 62.2 de la Convención. En palabras de la Corte, dicha reserva:

[...] tiene un alcance general, que termina por subordinar la aplicación de la Convención al derecho interno de Trinidad y Tobago en forma total y según lo dispongan sus tribunales nacionales. Todo esto implica que este instrumento de aceptación es manifiestamente incompatible con el objeto y fin de la Convención. Por lo tanto, no existe en el citado artículo (de la Convención) disposición alguna que faculte a Trinidad y Tobago para formular la restricción que hizo [párrafo 79 de la sentencia].

- La declaración efectuada por Trinidad y Tobago 
[...] facultaría a éste para decidir en cada caso concreto el alcance de su propia aceptación de la competencia contenciosa de la Corte en detrimento del ejercicio de la función contenciosa del Tribunal. Además, concedería al Estado la potestad discrecional para decidir qué asuntos puede conocer la Corte, lo que privaría el ejercicio de la competencia contenciosa del Tribunal de toda eficacia (párrafo 83).

- La aceptación de la declaración efectuada por el Estado demandado llevaría a una situación en la cual

[...] la Corte tendría como primer parámetro de referencia la Constitución del Estado y sólo subsidiariamente la Convención Americana, situación que acarrearía una fragmentación del orden jurídico internacional de protección de los derechos humanos y haría ilusorios el objeto y fin de la Convención (párrafo 84).

En consecuencia, la Corte concluyó que el Estado de Trinidad y Tobago no podía prevalerse de las limitaciones formuladas en su instrumento de aceptación de la jurisdicción obligatoria de la Corte Interamericana, dado que «dicha limitación es incompatible con el objeto y fin de la Convención» (párrafo 89 de la sentencia).

De esta manera, las excepciones relacionadas con la presunta falta de competencia ratione materiae de la Corte fueron desestimadas. Sin embargo, con posterioridad a estas sentencias sobre excepciones preliminares, el Estado demandado remitió una comunicación señalando que no participaría en las siguientes etapas procesales de estos casos. Este hecho dio lugar a que, en la sentencia sobre el fondo, la Corte retomará nuevamente el tema, pero ya no a propósito de una excepción sino como un pronunciamiento sobre la actuación del Estado durante el proceso.

\section{Medidas provisionales}

El artículo 63.2 de la Convención establece:

En casos de extrema gravedad y urgencia, y cuando se haga necesario evitar daños irreparables a las personas, la Corte, en los asuntos que éste conociendo, podrá tomar las medidas provisionales que considere pertinentes. Si se tratare de asuntos que aún no estén sometidos a su conocimiento, podrá actuar a solicitud de la Comisión.

El artículo en mención ofrece a la Corte la posibilidad de ordenar una medida tendiente a garantizar, de manera provisional, los derechos de las 
personas. De acuerdo con la Corte Interamericana, el objetivo de estas medidas en el derecho internacional de los derechos humanos,

Además de su carácter esencialmente preventivo, es proteger efectivamente derechos fundamentales, en la medida en que buscan evitar daños irreparables a las personas. El otorgamiento de [estas medidas], por su propio objeto y naturaleza jurídica, no puede, en circunstancia alguna, prejuzgar sobre el fondo del caso. ${ }^{8}$

En la práctica, es frecuente que la Corte Interamericana de Derechos Humanos «tome" medidas provisionales, para lo cual evalúa los siguientes aspectos:

- extrema gravedad de la amenaza,

- urgencia de las medidas requeridas y

- necesidad de evitar daños irreparables a las personas.

En el caso concreto, la CIDH solicitó en diferentes oportunidades a la Corte Interamericana la adopción de medidas provisionales a favor de personas condenadas a pena de muerte en Trinidad y Tobago, quienes se encontraban detenidos en espera de la ejecución de la sentencia, con el fin de preservar su vida e integridad personal. En términos generales, las solicitudes de la CIDH se basaron en el hecho que «la ejecución de estas personas antes de que la Comisión tuviera la oportunidad de dictaminar respecto de sus peticiones, les causaría un daño irreparable y tornaría ineficaces las eventuales decisiones que dicho organismo adoptara al respecto" (párrafo 26 de la sentencia sobre el fondo). Estas solicitudes recibieron respuestas favorables por parte de la Corte, y sus alcances se fueron ampliando hacia orras personas en similar situación.

Una de las personas a favor de la cual se adoptó una media provisional fue Joey Ramiah, mediante resolución de la Corte del 25 de mayo de 1999. En ella se ordenó al Estado de Trinidad y Tobago: "adoptar las medidas necesarias para preservar la vida e integridad personal de [entre otros, Joey Ramiah], con el objeto de no obstaculizar el trámite de sus casos ante el sistema interamericano". Sin embargo, a pesar de encontrarse protegido por una medida provisional, Joey Ramiah fue ejecutado el 4 de junio de

8 Resolución de la Corte Interamericana de Derechos Humanos del 27 de noviembre del 2002, sobre medidas provisionales solicitadas por la CIDH respecto a la República de Venezuela (Luisiana Ríos y otros vs. Venezuela, considerando 6).

9 Beltrán VARILlas, Cecilia. "Las medidas provisionales de la Corte Interamericana de Derechos Humanos: reflexiones sobre su uso como mecanismo de protección de la libertad de expresión». Revista Peruana de Jurisprudencia, año 6, n. ${ }^{\circ} 38$, abril del 2004, Lima, 2004, p. 91. 
1999, hecho que fue considerado por la Corte como una "privación arbitraria de la vida" (véase sección IV, numeral 4.2.1.2).

Debe destacarse que, en reiteradas ocasiones, la Corte solicitó al Estado de Trinidad y Tobago información referida al cumplimiento de las medidas provisionales. Sin embargo, no se presentó ninguna información sobre la situación de las presuntas víctimas.

Dos aspectos importantes deben señalarse a propósito de este caso. Por un lado, el incumplimiento de las medidas provisionales de la Corte respecto a Joey Ramiah y, por el otro, el incumplimiento de la obligación del Estado de informar sobre las medidas ordenadas. Sin lugar a dudas, este es uno de los puntos más débiles del sistema interamericano de protección de los derechos humanos. Como señala Beltrán Varillas, «si bien las medidas provisionales adoptadas por la Corte son importantes para lograr una protección inmediata ante violaciones de los derechos humanos de las personas, es imprescindible la voluntad política de los Estados en su cumplimiento efectivo". ${ }^{10}$

\section{Acumulación}

La acumulación es una institución procesal por medio de la cual se reúnen varios expedientes para sujetarlos a una tramitación común y fallarlos en una sola sentencia. La acumulación no hace perder a cada uno de los expedientes acumulados su individualidad; tiene por objetivo evitar sentencias contradictorias sobre cuestiones conexas y permite una economía del tiempo y del procedimiento. ${ }^{11}$

El artículo 28, inciso 1, del Reglamento de la Corte Interamericana permite la acumulación de casos y señala al respecto: «La Corte podrá, en cualquier estado de la causa, ordenar la acumulación de casos conexos entre sí cuando haya identidad de partes, objeto y base normativa".

Mediante resolución del 30 de noviembre del 2001, la Corte Interamericana resolvió acumular los tres casos a los que hemos hecho mención hasta el momento: el caso Hilaire, el caso Constantine y otros, y el caso Benjamin y otros. Para la Corte, entre estos ellos existía identidad de partes, objeto y base normativa. A partir de este momento, estos tres casos se conocieron simplemente como el caso Hilaire, Constantine, Benjamin y otros. Luego de esta acumulación, la Corte procedió a emitir su sentencia sobre el fondo.

$10 \quad$ Ibidem, p. 97.

"Pallares, Eduardo. Diccionario de Derecho Procesal Civil. 16. ad. México D.F: Porrúa, 1984 , p. 54. 


\section{Sentencia sobre el fondo}

El 21 de junio del 2002 fue expedida la sentencia sobre el fondo de la Corte Interamericana en el caso Hilaire, Constantine y Benjamin y otros vs. Trinidad y Tobago. En esta parte, nos corresponde evaluar el análisis realizado por la Corte sobre las diferentes violaciones a la Convención Americana. Sin embargo, tendremos nuevamente que referirnos de modo previo al tema de la competencia de la Corte, pues, a pesar de existir un pronunciamiento al respecto en las excepciones prelimares, el Estado demandado continuó desconociéndolo. ${ }^{12}$

\section{1. (De nuevo) sobre la competencia de la Corte Interamericana}

Hemos señalado anteriormente que el Estado de Trinidad y Tobago, por medio de excepciones preliminares, cuestionó la competencia de la Corte respecto a los hechos de este caso; estas fueron resueltas de manera independiente, pues todavía los procesos no habían sido acumulados. La Corte desestimó en su totalidad las excepciones mediante sentencias del 1 de septiembre del 2001.

Con posterioridad a estas decisiones, el Estado demandado señaló que no continuaría participando en este proceso. En este sentido, mediante una comunicación del 8 de febrero del 2002, informó que no asistiría a la audiencia pública convocada por la Corte e indicó lo siguiente:

El Gobierno de la República de Trinidad y Tobago debe declinar la invitación de la Corte para participar en la audiencia pública y la reunión previa a celebrarse el 20 y 21 de febrero de 2002 [...] En la toma de esta decisión el Gobierno de Trinidad y Tobago no pretende descortesía alguna hacia la Corte o su distinguido Presidente. Refleja la creencia del Estado de que, en ausencia de acuerdo especial alguno por parte de la República de Trinidad y Tobago reconociendo la competencia de la Corte en este asunto, la Corte Interamericana de Derechos Humanos no tiene competencia en relación con estos casos. ${ }^{13}$

Esta situación no resultaba novedosa para la Corte, pues en dos casos anteriores (seguidos contra el Estado del Perú) se había producido algo similar: el desconocimiento de la competencia contenciosa de la Corte, no mediante una excepción preliminar sino mediante una "comunicación" dirigida ante la Corte por parte del Estado demandado en el transcurso del pro-

12 Salvo referencia diferente, todas las menciones que a partir de ahora se realicen a una sentencia de la Corte corresponden a la sentencia sobre el fondo.

13 Este texto ha sido extraído del párrafo 16 de la sentencia sobre el fondo. 
ceso, que traía consigo su "alejamiento" del mismo. Nos referimos a lo ocurrido en los casos Tribunal Constitucional e Iucher Bronstein. Precisamente, las decisiones emitidas sobre este tema, en ambos casos, ${ }^{14}$ fueron empleadas por la Corte para pronunciarse sobre la posición asumida por Trinidad y Tobago. En términos generales, sus argumentos fueron similares a los expuestos en sus sentencias sobre excepciones preliminares. En este sentido, la Corte reafirmó que era «plenamente competente, en los términos de los artículos 62.3 y 78.2 de la Convención, para conocer el presente Caso y dictar sentencia».

De esta manera, la Corte reiteró su jurisprudencia sobre la ineficacia jurídica de cualquier medida mediante la cual se pretenda desconocer su competencia contenciosa sobre un caso concreto si la propia Corte ha decidido que tiene competencia para conocerlo. En el supuesto que un Estado discrepe de la decisión de la Corte y no desee seguir participando en el proceso, este continuará sin su intervención.

\subsection{Derechos analizados}

En su sentencia sobre el fondo, la Corte analizó si el Estado de Trinidad y Tobago era responsable de la afectación de los siguientes derechos reconocidos en la Convención Americana, respecto a las 31 personas que fueron juzgadas y condenadas a pena de muerte en aplicación de la Ley de delitos contra Personas:

- derecho a la vida,

- derecho al debido proceso,

- derecho a la protección judicial de los derechos fundamentales y

- derecho a la integridad personal. ${ }^{15}$

14 Caso Tribunal Constitucional, sentencia sobre competencia del 24 de setiembre de 1999, y Caso Ivcher Bronstein, sentencia sobre competencia del 24 de setiembre de 1999.

15 Por razones de extensión de este trabajo, no abordaremos este tema. Sin embargo, debe señalarse que la Corte evaluó las inadecuadas condiciones de reclusión de las personas privadas de libertad. Tomando en cuenta la información aportada por los informes periciales, consideró que las mismas constituían tratos crueles, inhumanos o degradantes, por lo que consideró afectados los derechos reconocidos en los artículos 5.1 y 5.2 de la Convención. Es interesante resaltar que, si bien la Comisión Interamericana había argumentado que dicha violación se produjo únicamente respecto a 21 personas, la Corte entendió que la situación descrita de las cárceles era generalizada en todo el sistema penitenciario de Trinidad y Tobago, por lo que la alegada violación de la Convención debía entenderse en perjuicio de todas las víctimas del presente caso. 
Debe señalarse que, en todas aquellas situaciones en las que la Corte consideró que se produjo una violación de la Convención, estableció asimismo que se había producido una violación del artículo 1.1 de este tratado, según el cual los Estados tienen la obligación de respetar y garantizar los derechos reconocidos en la Convención a todas las personas que se encuentren en su territorio, sin discriminación alguna. ${ }^{16}$ En términos generales, la obligación de respeto implica que los Estados se encuentran impedidos de realizar todo tipo de acto contrario a los derechos fundamentales, mientras que la de garantía implica que los Estados deben adoptar todas aquellas medidas que permitan a toda persona el goce y ejercicio de estos derechos, así como prevenir, investigar, sancionar y reparar cualquier afectación a los mismos.

\subsubsection{Derecho a la vida}

El artículo 4 de la Convención reconoce el derecho a la vida y establece medidas orientadas a garantizarlo. De los seis incisos relacionados con este derecho, cinco se refieren a la pena de muerte. El análisis que en este caso realiza la Corte y que se relaciona con el artículo 4 de la Convención se puede dividir en dos partes. Por un lado, el análisis de la Ley de Delitos contra la Persona, por medio de la cual fueron juzgadas y sentenciadas a pena de muerte todas las presuntas víctimas de este caso, y, por otra parte, el incumplimiento de las medidas provisionales adoptadas a favor de una de ellas.

\subsubsection{Legislación sobre pena de muerte incompatible con la Convención}

La Corte evaluó la compatibilidad entre la Ley de Delitos contra la Persona de Trinidad y Tobago, y los artículos 4.1, 4.2 y 2 de la Convención Americana sobre Derechos Humanos. La idea central respecto a este tema giró en torno a que dicha ley establecía una "pena de muerte obligatoria", lo que resultaba incompatible con la Convención. Veremos el análisis de cada uno de estos artículos por separado, su relación con el contenido de la mencionada ley y, finalmente, señalaremos las recomendaciones realizadas por la Corte a efectos de modificarla. ${ }^{17}$

16 El citado artículo 1.1 de la Convención señala textualmente lo siguiente: «Los Estados Partes en esta Convención se comprometen a respetar los derechos y libertades reconocidos en ella y a garantizar su libre y pleno ejercicio a toda persona que esté sujeta a su jurisdicción, sin discriminación alguna por motivos de raza, color, sexo, idioma, religión, opiniones políticas o de cualquier otra índole, origen nacional o social, posición económica, nacimiento o cualquier otra condición social» (subrayado nuestro).

17 Hay un aspecto adicional que agregar, y es el hecho de que la Corte empleó la institución del iura novit curia, que consiste en la facultad del juez de aplicar el derecho 


\section{a) Privación arbitraria de la vida (artículo 4.1 de la Convención)}

El artículo 4.1 de la Convención señala que «nadie será privado de la vida arbitrariamente». El término "arbitrariamente" resulta especialmente relevante, pues la prohibición de no privar a nadie de su vida solamente resulta aplicable a las situaciones que tengan esta característica, es decir, que sean arbitrarias. Aquella que no presente esta característica, no resultará incompatible con la Convención.

La pena de muerte implica un acto contrario al derecho a la vida, que si bien no está prohibido por la Convención, se encuentra limitado en cuanto a su aplicación, pues el artículo 4 de este tratado establece una serie de reglas que deben ser observadas por el Estado respecto a la pena capital (imposibilidad de aplicar esta sanción por delitos políticos a menores de edad, a mujeres embarazadas, entre otros). En su jurisprudencia, la Corte Interamericana ha agregado dos elementos adicionales, no mencionados de forma expresa en la Convención. Por un lado, el respeto a las garantías procesales en aquellos procesos que podrían concluir en una sentencia de pena de muerte - cuestión que resulta obvia, pues todo proceso debe respetar las garantías mínimas previstas en el artículo 8 de la Convención-y, por otra parte, lo que nos interesa resaltar, la necesidad de «atender a ciertas consideraciones propias de la persona del reo, las cuales pueden excluir la imposición o aplicación de la pena capital». ${ }^{18}$

En el caso objeto de análisis, la Corte Interamericana evaluó el contenido de la norma del Estado demandado que establecía la sanción de la pena de muerte para el tipo penal de homicidio (Ley de Delitos contra la Persona) y concluyó que esta no le permitía al juez evaluar las circunstancias particulares de cada caso, hecho que resultaba contrario a la prohibición de toda "privación arbitraria de la vida». Al respecto señaló (párrafo 103 de la sentencia):

La Corte constata que la Ley de Delitos contra la Persona de Trinidad y Tobago de 1925, ordena la aplicación de la pena de muerte de manera automática y genérica para el delito de homicidio intencional y desconoce que éste puede presentar diversos órdenes de gravedad. De ese modo, la referida Ley impide al juez considerar circunstancias básicas en la determinación del grado de culpabilidad y en la individualización de la pena, pues se limita a imponer, de modo indiscriminado, la misma sanción

objetivo necesario para la resolución del caso, aunque no haya sido invocado por las partes. En el caso concreto, las normas incorporadas por la Corte al análisis de este caso fueron los artículos 4.2 y 2 de la Convención.

18 Opinión consultiva OC-3/83, Restricciones a la pena de muerte (artículos 4.2 y 4.4 de la Convención Americana sobre Derechos Humanos), del 8 de setiembre de 1983, párrafo 55. 
para conductas que pueden ser muy diferentes entre si, lo que, a la luz del artículo 4 de la Convención Americana, es sumamente grave cuando se encuentra en riesgo el bien jurídico mayor, que es la vida humana, y constituye una arbitrariedad en los términos del artículo 4.1 de la Convención [subrayado nuestro].

El análisis realizado por la Corte incidió en el contenido de la norma, es decir, consideró que la violación de la Convención se originaba por la sola vigencia del dispositivo legal del Estado demandado, que contempla una "pena de muerte obligatoria". A partir de esto podria presumirse que la aplicación automática de esa norma por parte de los jueces resulta también contraria a la Convención, aunque no hay mayor evaluación de la Corte sobre la conducta de los jueces. Esto último hubiese sido interesante a fin de constatar o negar si los delitos cometidos por las presuntas víctimas resultaban de tal gravedad que correspondía aplicar la pena capital. El análisis del caso estrictamente sobre la base del contenido de la norma se corrobora con el siguiente argumento de la Corte (párrafo 104 de la sentencia):

Conviene precisar que la Ley de Delitos contra la Persona ofrece dos particularidades principales: a) en cuanto a la determinación de la responsabilidad penal, solamente autoriza al juzgador para encontrar responsable a una persona por homicidio intencional basándose en la categoría del delito, sin que pueda tomar en cuenta las condiciones personales del justiciable ni las circunstancias particulares del delito, y b) en lo que toca a la determinación de la sanción, impone de manera mecánica y genérica la aplicación de la pena de muerte para todo culpable de homicidio intencional e impide que dicha sanción pueda ser modificada por la vía de la revisión judicial.

Entendemos, en consecuencia, que para la Corte, los jueces de Trinidad y Tobago no podían en absoluto moderar los alcances de la ley a las exigencias del caso o incluso inaplicarla a un caso concreto. Del razonamiento de la Corte no se puede afirmar que esto así haya ocurrido, pues se pronuncia en abstracto sobre la norma y no sobre resoluciones judiciales concretas, lo que hubiese sido interesante. Esto es compatible con la tendencia del tribunal a considerar que un Estado tiene responsabilidad internacional por el solo hecho de expedir normas cuyo contenido sea incompatible con la Convención. ${ }^{19}$

Basándose en los argumentos expuestos, la Corte consideró que el Estado demandado violó el artículo 4.1 de la Convención en conjunción con el artículo 1.1 .

19 En un principio, la Corte no tuvo esta tendencia, pero luego la asumió. Este cambio se aprecia, por ejemplo, en la sentencia sobre el fondo en el caso Loayza Tamayo, del 17 de setiembre de 1997, párrafo 68, en la cual la Corte declaró incompatibles con la Convención dos decretos leyes emitidos por el Estado demandado (Perú). 
b) Aplicación de la pena de muerte a los delitos más graves (artículo 4.2 de la Convención)

El artículo 4.2 de la Convención señala que, en los países que no han abolido la pena de muerte, esta solamente podrá ser impuesta para el caso de «los delitos más graves». En el caso objeto de análisis, la Corte se refirió a este tema, relacionándolo además con el artículo 4.1, analizado en el acápite anterior. $\mathrm{Al}$ respecto señaló:

Una de las formas que puede asumir la privación arbitraria de la vida, en los términos de la prohibición del artículo 4.1 de la Convención, es la que se configura cuando, en los países en que aún existe la pena de muerte, ésta se utiliza para castigar delitos que no presentan las características de máxima gravedad, como ocurre en Trinidad y Tobago en virtud de lo dispuesto por la Ley de Delitos contra la Persona, es decir, cuando la aplicación de esa pena no se ciñe a las previsiones del artículo 4.2 de la Convención Americana.

Basándose en este argumento, la Corte consideró que el Estado demandado violó el artículo 4.2 de la Convención en conjunción con el artículo 1.1.

Dado que el único argumento empleado por la Corte respecto al artículo 4.2 fue el anteriormente citado, no queda claro si para este tribunal el tipo penal de homicidio previsto en la Ley de Delitos contra la Persona no era tan grave que pudiera justificar la aplicación de la pena de muerte o si el hecho de que los jueces tuvieran que aplicarla de manera automática y obligatoria, sin posibilidad de evaluar cada situación concreta, hacía imposible separar los hechos realmente graves de aquellos otros que no lo eran, aplicándose en consecuencia tal sanción a supuestos que no la justificarían. Sin embargo, en tanto este tema es abordado de conformidad con lo señalado por la Corte respecto a la violación del artículo 4.1 de la Convención, consideramos que la segunda opción refleja la posición de la Corte.

c) Obligación del Estado de adoptar medidas que hagan efectivos los derechos fundamentales (artículo 2 de la Convención)

Al ratificar la Convención Americana, los Estados asumen un conjunto de obligaciones respecto a los derechos que esta reconoce. En el caso concreto, la Corte dedicó una sección especial a evaluar si el Estado demandado había desconocido la obligación prevista en el artículo 2 , según la cual:

Si en el ejercicio de los derechos y libertades mencionados en el artículo 1 no estuviere ya garantizado por disposiciones legislativas o de otro carácter, los Estados partes se comprometen a adoptar, con arreglo a sus procedimientos constitucionales y a las disposiciones de esta Convención, las medidas legislativas o de otro carácter que fueren necesarias para hacer efectivos tales derechos y libertades [subrayado nuestro]. 
Al interpretar los alcances de esta norma, la Corte Interamericana ha señalado que los Estados partes tienen la obligación general de adecuar su derecho interno a las normas de la Convención, para garantizar los derechos consagrados en esta. Las disposiciones de derecho interno que se adopten para tales fines han de ser efectivas, es decir, el Estado tiene la obligación de consagrar y adoptar en su ordenamiento jurídico interno todas las medidas necesarias para que lo establecido en la Convención sea realmente cumplido y puesto en práctica. ${ }^{20}$ De acuerdo con la Corte:

Si los Estados tienen, de acuerdo con el artículo 2 de la Convención Americana, la obligación positiva de adoptar las medidas legislativas que fueren necesarias para garantizar el ejercicio de los derechos reconocidos por la Convención, con mayor razón están en la obligación de no expedir leyes que desconozcan esos derechos u obstaculicen su ejercicio, y la de suprimir o modificar las que tengan estos últimos alcances. De lo contrario, incurren en violación del artículo 2 de la Convención [párrafo 113 de la sentencia, subrayado nuestro].

La Corte Interamericana ha tenido oportunidad de conocer diferentes casos en los que constató la existencia de normas contrarias a los derechos reconocidos en la Convención, y eso dio lugar a que declarase la responsabilidad internacional del Estado involucrado por violación del artículo 2 de la Convención. Algunos ejemplos son especialmente útiles para comprender este tema:

- En el caso Suárez Rosero, la Corte señaló que una disposición legal del Estado demandado (Ecuador) violaba por sí misma el artículo 2 de la Convención. Se trataba de una norma que dejaba a las personas acusadas de un delito determinado (vinculado con la comercialización de sustancias estupefacientes y psicotrópicas) desprovistas de protección legal a su derecho a la libertad personal. $\mathrm{Al}$ respecto, la Corte dijo que la norma en cuestión despojaba

[...] a una parte de la población carcelaria de un derecho fundamental en virtud del delito imputado en su contra y, por ende, lesiona[ba] intrínsecamente a todos los miembros de dicha categoría de inculpados. En el caso concreto del señor Suárez Rosero esa norma ha sido aplicada y le ha producido un perjuicio indebido. La Corte hace notar, además, que, a su juicio, esa norma per se viola el artículo 2 de la Convención Americana, independientemente de que haya sido aplicada en el caso [subrayado nuestro]. ${ }^{21}$

20 Caso La Última Tentación de Cristo (Olmedo Bustos y otros), sentencia del 5 de febrero de 2001, párrafo 87.

21 Caso Suárez Rosero, sentencia del 12 de noviembre de 1997, párrafo 98. 
- En el caso Barrios Altos, la Corte señaló que, a causa de la adopción de leyes incompatibles con la Convención - normas de amnistía que impedían la investigación de violaciones a los derechos humanos-, el Estado demandado (Perú) incumplió la obligación de adecuar el derecho interno a este tratado, consagrada en el artículo 2 del mismo. ${ }^{22}$

En el caso que estamos analizando, la Corte reiteró esta posición y dejó en claro que la sola existencia de la Ley de Delitos contra la Persona hacía responsable al Estado de Trinidad y Tobago por violación del artículo 2 de la Convención, independientemente de la situación jurídica de las presuntas víctimas a quienes se les aplicó la ley. En palabras de la Corte (párrafos 116 y 117 de la sentencia):

La Corte estima que aun cuando no se ha ejecutado a 31 de las presuntas víctimas en este caso, es posible declarar una violación del artículo 2 de la Convención, en virtud de que la sola existencia de la Ley de Delitos contra la Persona es per se violatoria de esa disposición convencional. [...]

En virtud de que Trinidad y Tobago no ha adecuado su legislación a la Convención, ha incumplido la obligación impuesta a los Estados partes por el artículo 2 de la misma [subrayado nuestro].

¿Estamos ante un control abstracto de las normas internas de los Estados a fin de evaluar su compatibilidad con la Convención Americana? En principio, podríamos responder de modo afirmativo, pero la Corte solo podría pronunciarse sobre estos temas en un caso contencioso, si en el problema de fondo se encuentra involucrada una norma aparentemente incompatible con la Convención, haya sido o no aplicada en perjuicio de una persona.

d) Modificaciones legales y nuevos procesos ordenados por la Corte

Hemos visto que la Corte Interamericana consideró que el Estado de Trinidad y Tobago violó el derecho a la vida reconocido en los artículos 4.1 y 4.2 de la Convención Americana, así como la obligación contenida en el artículo 2 del mismo tratado, en perjuicio de las víctimas del presente caso y como consecuencia de la vigencia y aplicación de la Ley de Delitos de la Persona. Los efectos jurídicos de esta decisión resultan importantes. En el punto 8 de la parte resolutiva de la sentencia la Corte señaló: «[El Estado demandado] debe abstenerse de aplicar la Ley de Delitos contra la Persona de $1925 \mathrm{y}$, dentro de un plazo razonable, debe modificarla adecuándola a

2 Caso Barrios Altos, sentencia del 14 de marzo de 2001, párrafo 42. 
las normas internacionales de protección de los derechos humanos, en los términos expuestos en el párrafo 212 de la presente Sentencia».

El citado párrafo 212 de la sentencia establece que el Estado deberá modificar la mencionada ley en aspectos específicos, de tal manera que se incluyan «diversas categorías (tipos penales) de homicidio intencional, que correspondan a la diversa gravedad de los hechos, tomando en cuenta las circunstancias del delito y del justiciable, y [...] una gradación de los niveles de severidad de la pena que guarde relación con la gravedad de los hechos y con la culpabilidad del imputado". Como consecuencia de estas reformas, señala además que el Estado demandado deberá tramitar nuevamente los procedimientos penales contra las personas que fueron afectadas en sus derechos como consecuencia de la Ley de Delitos contra la Persona, en los cuales se deberá aplicar la nueva legislación. ${ }^{23}$

Tomando en cuenta lo dispuesto por la Corte, entendemos que si el Estado demandado no modifica su ordenamiento jurídico interno de conformidad con lo señalado en la sentencia o no llevase a cabo los nuevos juicios, se presentaría una situación de incumplimiento permanente de ella y, además, una violación permanente art. 2 de la Convención.

\subsubsection{Incumplimiento de medidas provisionales}

Como señalamos anteriormente, la CIDH solicitó a la Corte Interamericana la adopción de medidas provisionales a favor de varias personas que fueron juzgadas sobre la base de la Ley de Delitos contra la Persona y condenadas a pena de muerte. Uno de los condenados que obtuvo una medida provisional a su favor fue Joey Ramiah, mediante resolución del 25 de mayo de 1999. Sin embargo, al poco tiempo, el 4 de junio de 1999, Joey Ramiah fue ejecutado. Para la Corte, este acto constituyó una "privación arbitraria de la vida», expresamente prohibida por el artículo 4 de la Convención. En sus fundamentos señaló (párrafo 198 de la sentencia):

La Corte considera que la ejecución de Joey Ramiah por parte de Trinidad y Tobago constituye una privación arbitraria del derecho a la vida. Esta situación se agrava porque la vícrima se encontraba amparada por una Medida Provisional ordenada por este Tribunal, la cual expresamente señalaba que debía suspenderse la ejecución hasta que el caso fuera resuelto por el sistema interamericano de derechos humanos [subrayado nuestro].

23 La Corte no analiza si esto sería conforme con el non bis in idem, reconocido en el artículo 8.4 de la Convención. 
No hubo mayores fundamentos sobre el tema por parte de la Corte, pues la ejecución de Joey Ramiah fue una situación concreta que consideró lesiva del derecho a la vida, por lo que si no hubiese existido una medida provisional su decisión hubiese sido la misma. Lamentablemente, esto no queda tan claro en el fallo de la Corte, pues aborda la ejecución de Joey Ramiah combinando dos temas: la privación arbitraria de la vida y el incumplimiento de las medidas provisionales. Es lo primero lo que origina la condena de la Corte, que según sus propias palabras, "se agrava" por lo segundo, aunque esto último no genera una consecuencia jurídica diferente. Quizá hubiese sido adecuado que la Corte se pronuncie sobre esto en un sentido afirmativo. La omisión al respecto no hace sino debilitar la eficacia de estas medidas.

\subsubsection{Debido proceso y protección judicial de los derechos fundamentales}

\subsubsection{Aspectos generales}

Los artículos 8 y 25 de la Convención reconocen, respectivamente, el derecho al debido proceso y a la protección judicial de los derechos fundamentales, que han sido objeto de un importante desarrollo a través de la jurisprudencia de la Corte Interamericana de Derechos Humanos.

\section{a) Debido proceso}

La Convención Americana sobre Derechos Humanos desarrolla los alcances del derecho al debido proceso en su artículo 8, denominado «Garantías Judiciales», de modo inapropiado, como la misma Corte Interamericana ha tenido oportunidad de señalarlo. ${ }^{24}$

La Corte Interamericana de Derechos Humanos ha emitido importantes decisiones relacionadas con los derechos reconocidos en el artículo 8 de la Convención. Sin embargo, todavía no existe sobre todos ellos una amplia jurisprudencia, pues las sentencias de la Corte han incidido principalmente en algunos temas o se han referido de manera general a otros. ${ }^{25}$

24 Para la Corte Interamericana, la expresión "garantías judiciales» hace referencia a los mecanismos o recursos judiciales que permiten proteger, asegurar o hacer valer la titularidad o el ejercicio de un derecho, por lo que su uso para denominar al conjunto de derechos reconocidos en el artículo 8 de la Convención puede generar confusión, pues en esta disposición "no se consagra un medio de esa naturaleza en sentido estricto" ni contiene "un recurso judicial propiamente dicho». Véase al respecto las opiniones consultivas OC-8/87, del 30 de enero de 1987 y OC-9/87, del 6 de octubre de 1987.

25 Una síntesis de las sentencias de la Corte Interamericana sobre el debido proceso puede consultarse en nuestro trabajo El debido proceso en las decisiones de la Corte Interamericana de Derechos Humanos. Lima: Comisión Andina de juristas, octubre del 2003. 
La afectación de las garantías del debido proceso reconocidas en la Convención puede originar diferentes consecuencias. Así, por ejemplo, si un proceso se lleva a cabo con violación del derecho al tribunal competente, independiente e imparcial, tal situación dará lugar a la realización de nuevos procesos ante tribunales que reúnan estas exigencias, o si un proceso tiene un plazo excesivo de duración, se deberán adoptar las medidas necesarias para una pronta resolución judicial.

Conforme se analice cada una de las garantías procesales afectadas en el caso Hilaire, Constantine, Benjamín y otros, se hará referencia a las consecuencias jurídicas que trajo consigo su inobservancia.

b) Protección judicial de los derechos fundamentales

El artículo 25 de la Convención Americana reconoce el derecho a la protección judicial de los derechos fundamentales. En este sentido dispone, en su inciso 1, que toda persona tiene derecho a contar con «un recurso sencillo y rápido o cualquier otro recurso efectivo ante los jueces o tribunales competentes, que la ampare contra actos que violen sus derechos fundamentales reconocidos por la Constitución, la ley o la presente Convención».

Una revisión de los casos resueltos en el sistema interamericano de protección de los derechos humanos permite identificar hasta seis situaciones que son lesivas del derecho a la protección judicial de los derechos fundamentales:

1. Impedimentos legales para la protección judicial de los derechos fundamentales. Esto ocurre cuando los Estados establecen normas mediante las que impiden a las personas presentar un recurso judicial para la tutela de sus derechos. ${ }^{26}$

2. Situaciones que impiden presentar una demanda de protección judicial de los derechos fundamentales. Aparte de un impedimento legal, pueden presentarse otras situaciones que, en los hechos, impiden que una persona pueda presentar un recurso judicial para la tutela de sus derechos, y eso puede ir desde la inexistencia de un mecanismo judicial idóneo para tal objetivo hasta una ausencia de actividades por parte de los órganos jurisdiccionales del Estado que no permita el acceso de los ciudadanos a los tribunales. ${ }^{27}$

25 A modo de ejemplo, se puede revisar la sentencia sobre el fondo de la Corte Interamericana en el caso Loayza Tamayo, del 17 de setiembre de 1997. En este caso, la legislación emitida en el Estado demandado (Perú) prohibía la presentación de habeas corpus a favor de las personas procesadas por el delito de traición a la patria, sea para salvaguardar su libertad personal o cuestionar la legalidad de su detención, hecho que fue considerado por la Corte como violatorio del artículo 25 de la Convención.

z A modo de ejemplo, se puede revisar el informe 1/95 de la $\mathrm{CIDH}$ (caso 11.006, Alan 
3. Situaciones que impiden resolver una demanda de protección judicial de los derechos fundamentales. Estos casos se presentan cuando, a pesar de haberse logrado presentar un recurso judicial para la protección de los derechos fundamentales, este no puede ser resuelto por las autoridades judiciales, por diferentes circunstancias. ${ }^{28}$

4. Impedimento para presentar una demanda de protección judicial de los derechos fundamentales durante los estados de excepción. Al respecto, la Corte Interamericana de Derechos Humanos ha señalado, de forma clara, que bajo ninguna circunstancia puede impedirse a una persona, durante los estados de excepción, de acudir ante las autoridades judiciales a efectos de solicitar la protección de sus derechos fundamentales. ${ }^{29}$

5. Incumplimiento de resoluciones judiciales adoptadas para proteger derechos fundamentales. Esto ocurre cuando, a pesar de haberse podido presentar y resolver un recurso judicial para proteger los derechos fundamentales, las decisiones adoptadas en el marco de estos procesos se incumplen. ${ }^{30}$

6. Violación de las garantias del debido proceso en el marco de los procesos judiciales destinados a la protección de los derechos fundamentales. El derecho reconocido en el artículo 25 de la Convención se ve afectado, asimismo, cuando, en el marco de los procesos judiciales previstos para la tutela de los derechos fundamentales, no se respetan las garantías del debido proceso. Para la Corte, la relación entre los artículos 8 (debido proceso) y 25 (protección judicial) de la Convención Americana implica la consagración del derecho de las victimas a obtener protección judicial de conformidad con el debido

García Pérez), del 7 de febrero de 1995. En este caso se quiso presentar un habeas corpus a favor de un ex presidente de la República del Perú, pues existían indicios suficientes que demostraban una persecución en su contra durante el golpe de Estado que ocurrió en este país el 5 de abril de 1992. Para tal efecto, su esposa acudió a las instalaciones del Palacio de Justicia (una de las sedes del Poder Judicial), pero este se encontraba resguardado por las fuerzas armadas, «las cuales impidieron ingresar al mismo o mantener contacto con los magistrados de turno".

28 A modo de ejemplo se puede revisar la sentencia sobre el fondo de la Corte Interamericana en el caso Durand y Ugarte, del 16 de agosto del 2000. En este caso, si bien se pudo presentar un habeas corpus a favor de personas privadas de libertad en establecimientos penitenciarios, cuyo paradero era incierto luego de la debelación de un motín, los jueces no pudieron ingresar a dichos penales pues fueron declarados "zonas militares restringidas", y eso impidió "investigar y determinar el paradero de las personas a favor de las cuales se había interpuesto el recurso".

2 Se pueden revisar al respecto la opinión consultiva OC-8/87, del 30 de enero de 1987 (EI hábeas corpus bajo suspensión de garantías) y la opinión consultiva OC-9/87, del 6 de octubre de 1987 (garantías judiciales en estados de emergencia).

- A modo de ejemplo, se puede revisar la sentencia sobre el fondo de la Corte Interamericana en el caso Cesti Hurtado, del 29 de setiembre de 1999. En este caso, la sentencia de habeas corpus a favor de esta persona, emitida por los tribunales del Estado demandado (Perú), fue incumplida por quienes estaban obligados a hacerlo. 
proceso legal. ${ }^{31}$ En este sentido, en el marco de los procesos establecidos para la protección judicial de los derechos fundamentales, también se deben respetar las garantías del debido proceso. ${ }^{32}$

\subsubsection{El caso concreto}

En caso objeto de análisis, la CIDH alegó diferentes violaciones al debido proceso y al derecho a la protección judicial de los derechos fundamentales. En su sentencia, la Corte agrupó las violaciones alegadas en dos temas: la afectación del plazo razonable de duración de un proceso y la ausencia de asistencia legal adecuada. ${ }^{33}$

a) Afectación del plazo razonable de duración de un proceso

El artículo 8.1 de la Convención Americana señala que toda persona tiene derecho a ser oída dentro de un plazo razonable. De acuerdo con la Corte Interamericana, este consiste en "obtener respuesta, dentro de un plazo razonable, a las demandas y solicitudes planteadas a las autoridades judicialesm. ${ }^{34}$

La Corte ha dejado en claro que el concepto de "plazo razonable" no resulta de sencilla definición. ${ }^{35}$ Para establecer un lapso preciso que constituya el límite entre la duración razonable y la prolongación indebida de un proceso, la Corte ha señalado que es necesario examinar las circunstancias particulares de cada caso. En este sentido ha manifestado:

Esta Corte comparte el criterio de la Corte Europea de Derechos Humanos, la cual ha analizado en varios fallos el concepto de plazo razonable y ha dicho que se debe tomar en cuenta tres elementos para determinar la razonabilidad del plazo en el cual se desarrolla el proceso: a) la complejidad del asunto, b) la actividad procesal del interesado y c) la conducta de las autoridades judiciales [subrayado nuestro] ${ }^{36}$

31 Caso Tribunal Constitucional, sentencia del 31 de enero del 2001, párrafo 103.

32 A modo de ejemplo, se puede revisar la sentencia sobre el fondo de la Corte Interamericana en el caso Tribunal Constitucional, del 31 de enero del 2001. En este caso, la Corte constató la falta de imparcialidad de los magistrados que resolvieron un proceso de amparo iniciado por personas afectadas en sus derechos, así como la demora en su resolución, lo que, a su criterio, implicó que dicho recurso estuviera destinado al fracaso, ya que mediante él no se podía remediar la situación lesiva de los derechos invocados, y eso significaba una violación del artículo 25 de la Convención.

33 Se alegaron otros actos lesivos, pero la Corte no consideró necesario pronunciarse sobre todas ellos, pues los entendió comprendidos en estos dos supuestos.

34 Caso Las Palmeras, sentencia del 6 de diciembre del 2001, párrafo 57.

35 Caso Genie Lacayo, sentencia del 29 de enero de 1997, párrafo 77.

36 Caso Genie Lacayo, sentencia del 29 de enero de 1997, párrafo 77; y caso Suárez Rosero, sentencia del 12 de noviembre de 1997, párrafo 72 . 
Asimismo, la Corte Interamericana ha considerado importante tomar otro criterio desarrollado por la Corte Europea para determinar la razonabilidad del plazo de duración de un proceso: el análisis global del procedimiento. ${ }^{37}$

La Corte, en consecuencia, no opta por precisar un plazo determinado en días calendarios o naturales como el máximo de duración aplicable a un proceso, sino que brinda unos criterios a ser evaluados por la judicatura para precisar si se afecta el derecho al plazo razonable de duración de un proceso, según las circunstancias que se presenten en cada situación concreta. A la vez que en el artículo 8.1 , la referencia al plazo razonable de duración de un proceso también se encuentra prevista en el artículo 7.5 de la Convención, que aborda el tema de la libertad personal. Esta norma seńala: "Toda persona detenida o retenida debe ser llevada, sin demora, ante un juez u otro funcionario autorizado por la ley para ejercer funciones judiciales y tendrá derecho a ser juzgada dentro de un plazo razonable o a ser puesta en libertad, sin perjuicio de que continúe el proceso [...]» (subrayado nuestro). Como se aprecia, el derecho al plazo razonable de duración de un proceso tiene una connotación adicional en el ámbito de los procesos penales, pues en caso de que estos tengan una duración excesiva, las personas inculpadas que se encuentran detenidas tienen derecho a que se decrete su libertad. Para la Corte, este derecho «tiene como finalidad impedir que los acusados permanezcan largo tiempo bajo acusación y asegurar que ésta se decida prontamentem. ${ }^{38}$

Tema de especial interés para el cómputo del plazo razonable de duración de un proceso lo constituyen las fechas que se deben considerar como de inicio y final del mismo. Estas varían según las circunstancia de cada situación. Así, la fecha de inicio del cómputo del plazo razonable puede ser aquella en la cual se produjo la detención de una persona o la fecha de la primera resolución con la que se da inicio a un proceso judicial en su contra. En todo caso, la Corte ha considerado que «el proceso termina cuando se dicta sentencia definitiva y firme en el asunto, [...] y que, particularmente en materia penal, dicho plazo debe comprender todo el procedimiento, incluyendo los recursos de instancia que pudieran eventualmente presentarsen. ${ }^{39}$

En el caso Hilaire, Constantine, Benjamín y otros, la Corte consideró afectado el derecho al plazo razonable de duración de un proceso y, en consecuencia, declaró la responsabilidad del Estado demandado por violación

37 Caso Genie Lacayo, sentencia del 29 de enero de 1997, párrafo 81.

3 Caso Suárez Rosero, sentencia del 12 de noviembre de 1997, párrafo 70.

39 Caso Suárez Rosero, sentencia del 12 de noviembre de 1997, párrafo 71. 
de los artículos 8.1 y 7.5 de la Convención, en forma conjunta con los artículos 1.1 y 2 . Su argumento principal se basó en los hechos expuestos por la CIDH y que aparecen a lo largo de la sentencia. En síntesis, esta señaló:

[En los casos seguidos contra las presuntas víctimas en aplicación de la Ley de Delitos contra las Personas] ninguno de ellos fue resuelto en menos de cuatro años, tomando en cuenta el lapso transcurrido entre la detención del inculpado y la sentencia en la apelación; y [...] algunas de las victimas estuvieron en prisión, antes de ser llevadas a juicio, durante cerca de siete años, y por lo tanto, experimentaron demoras de aproximadamente doce años entre la detención y la resolución de sus apelaciones [párrafo 121 de la sentencia, subrayado nuestro].

La Corte no hace mayor análisis sobre el tema, pues no evalúa ninguno de los criterios establecidos en su jurisprudencia para determinar la razonabilidad de la duración excesiva de un proceso. Por ello, se puede deducir que si este dura hasta cuatro años (incluida la sentencia de apelación) ya de por sí se produce una violación del derecho que estamos analizando.

Otro argumento empleado por la Corte en su sentencia es el hecho que la Constitución del Estado demandado no tuviese un reconocimiento expreso del "derecho a un juicio pronto o dentro de un plazo razonablem, hecho que "no se ajusta a lo dispuesto en la Convención" (párrafo 152.a de la sentencia). Sin embargo, tampoco hace mayor análisis al respecto, por lo que puede concluirse que dicha omisión es per se violatoria de las obligaciones del Estado de adoptar medidas para garantizar los derechos reconocidos en la Convención. Este hecho es particularmente interesante, pues si bien un derecho fundamental puede tener otro tipo de reconocimiento, como por ejemplo en el ámbito legal o por medio de la jurisprudencia, la Corte considera contrario a la Convención que no exista una mención del mismo en el texto constitucional.

Teniendo en cuenta estos argumentos, la Corte consideró que el Estado demandado violó el derecho a ser juzgado dentro de un plazo razonable $y$, con ello, las disposiciones contenidas en los artículos 7.5 y 8.1 en conjunción con los artículos 1.1 y 2 de la Convención.

b) Ausencia de asistencia legal adecuada

Hemos señalado anteriormente que el derecho a la protección judicial de los derechos fundamentales se ve afectado cuando se presentan situaciones o circunstancias que impiden presentar un recurso para la tutela de estos derechos. En el caso Hilaire, Constantine, Benjamin y otros, la Corte señaló que se presentó un impedimento para lograr una tutela judicial de 
los derechos fundamentales, en tanto que no existió una asistencia legal adecuada para presentar un recurso de revisión de las resoluciones judiciales que establecían las condenas a pena de muerte. En palabras de la Corte: «se impidió el empleo de este recurso en cuanto el Estado no proporcionó a los inculpados asistencia jurídica a fin de que pudieran ejercitarlo efectivamente, y de esta forma constituyó un recurso ilusorio para aquéllos» (párrafo $152 . b$ de la sentencia).

De esta decisión, se puede deducir que un acto contrario al derecho a la protección judicial de los derechos fundamentales se produce cuando no se ofrece por parte del Estado la asistencia jurídica necesaria para la presentación del recurso destinado a conseguir esa protección.

Basándose en estos argumentos, la Corte consideró que el Estado demandado violó los artículos 8 y 25 de la Convención en conjunción con el artículo 1.1 .

\subsection{Impedimento de nuevas ejecuciones}

Hemos dejado para el final un tema que se encuentra relacionado con el conjunto de las violaciones a la Convención ocurridas en el presente caso. Se trata de una medida adoptada por la Corte que resulta particularmente novedosa. Nos referimos al hecho de que la Corte haya ordenado, por equidad, que no se ejecute a ninguna de las personas cuyos derechos se vieron afectados en este caso. En palabras del tribunal (párrafo 215 de la sentencia y punto resolutivo 11):

[...] la Corte debe tomar en cuenta que el Estado ha violado en contra de todas o algunas de las víctimas de este caso los derechos consagrados en los artículos 4.1, 4.2 y 4.6, 5.1 y $5.2,7.5,8.1$ y 25 , en relación con los artículos 1.1 y 2 , de la Convención, a causa de un conjunto de circunstancias que han sido descritas en esta sentencia, entre las cuales se cuenta el hecho de que las víctimas han sido juzgadas en aplicación de una ley que es incompatible con la Convención Americana. Con base en ello, la Corte estima que [...] debe disponer que el Estado con fundamento en la equidad, se abstenga de ejecutar, en cualquier caso, y cualesquiera que sean los resultados de los nuevos juicios a que se refiere el párrafo anterior, $\mathrm{e}$ incluso con independencia del hecho de si esos nuevos juicios se realizan o no, [a las 31 personas que fueron juzgadas y sentenciadas en aplicación de la Ley de Delitos contra la Persona].

En relación con este tema, entendemos que la Corte toma en consideración que todas las violaciones realizadas por el Estado demandado a las víctimas de este caso han sido de tal magnitud que son razón suficiente para establecer la prohibición de ejecutarlas, incluso en el supuesto que fueran 
encontradas culpables luego de ser sometidas a un nuevo proceso, bajo una legislación emitida conforme a los lineamientos ordenados por la Corte. Así entendemos la expresión "con fundamento en la equidad", que se subraya en el párrafo transcrito, en tanto que la Corte no ofrece mayores alcances al respecto. Esto puede también entenderse como una manera ingeniosa, por parte de la Corte, de evitar la aplicación de la pena capital, aunque sea en estos casos. Un paso adelante igual de interesante hubiese sido que la Corte señalara que tampoco podían ser ejecutadas todas aquellas personas que en el Estado de Trinidad y Tobago hubiesen sido condenadas por la cuestionada Ley de Delitos contra la Persona, aunque no hubiesen formado parte de este caso concreto. ${ }^{40}$

\section{Supervisión y cumplimiento de la sentencia}

Por lo general, la Corte se reserva en sus sentencias la facultad de supervisar el cumplimiento de su fallo. En el caso concreto, los puntos resolutivos 16 y 17 de la sentencia sobre el fondo contienen información relevante sobre este tema. En estos se señala:

[...] el Estado (de Trinidad y Tobago) debe rendir a la Corte Interamericana de Derechos Humanos cada seis meses, a partir de la notificación de la presente Sentencia, un informe sobre las medidas tomadas para darle cumplimiento, $y$

[La Corte] supervisará el cumplimiento de esta sentencia y dará por concluido el presente Caso una vez que el Estado haya dado cabal aplicación a lo dispuesto en el presente fallo.

Uno de los aspectos más trascendentales del sistema interamericano de protección de los derechos humanos radica en el cumplimiento de los fallos de la Corte. El artículo 68.1 de la Convención señala al respecto que los Estados partes en la Convención se comprometen a cumplir sus decisiones. Lamentablemente, no existen otras disposiciones sobre la materia que con-

- En un caso anterior, la Corte se pronunció sobre los efectos generales de su decisión de declarar incompatible con la Convención dos normas internas de un Estado, independientemente del caso concreto a propósito del cual declaró esta incompatibilidad. Nos referimos al caso Barrios Altos, en el que la precisión sobre este tema se dio mediante una interpretación sobre la sentencia del fondo, del 3 de setiembre del 2001. Al respecto señaló: "La promulgación de una ley manifiestamente contraria a las obligaciones asumidas por un Estado parte en la Convención constituye per se una violación de ésta y genera responsabilidad internacional del Estado. En consecuencia, la Corte considera que, dada la naturaleza de la violación constituida por las leyes de amnistía No. 26479 y No. 26492, lo resuelto en la sentencia de fondo en el caso Barrios Altos tiene efectos generales". 
tengan algún mecanismo de coerción para el cumplimiento de las sentencias. El artículo 65 de la Convención únicamente contempla la intervención de un órgano político. ${ }^{41}$

En el caso objeto de análisis, la ausencia de estos mecanismos de coerción puede ser la razón del permanente incumplimiento de la sentencia de la Corte por parte del Estado demandado. En el informe anual de la Corte Interamericana de Derechos Humanos correspondiente al 2003, encontramos la referencia correspondiente a este caso en la sección denominada «Falta del cumplimiento al deber de informar a la Corte». En ella se lee lo siguiente: ${ }^{42}$

En el caso Hilaire, Constantine, Benjamín y otros vs. Trinidad y Tobago, el Estado no ha cumplido con su deber de informar a la Corte sobre las medidas que haya adoptado para dar cumplimiento efectivo a lo ordenado por el Tribunal en su sentencia sobre el fondo y reparaciones del presente caso.

Al respecto, la Corte insta a la Asamblea General de la OEA que exhorte al Estado de Trinidad y Tobago para que informe al Tribunal sobre las medidas adoptadas para dar cumplimiento con su sentencia [subrayado nuestro].

\section{Reflexiones finales}

La creación y funcionamiento de tribunales internacionales con capacidad para emitir sentencias de cumplimiento obligatorio por parte de los Estados representa el punto más alto alcanzado en el ámbito de la protección internacional de los derechos humanos. En el sistema interamericano, la labor realizada por la Corte Interamericana merece especial atención y estudio, pues se encuentra en constante evolución y perfeccionamiento, en atención a los nuevos que conoce y que le permiten pronunciarse de manera progresiva sobre diferentes disposiciones de la Convención Americana sobre Derechos Humanos. En este sentido, el análisis del caso Hilaire, Constantine, Benjamín y otros, seguido contra el Estado de Trinidad y Tobago, constituye una decisión de especial importancia, por ser el primer caso contencioso resuelto por la Corte relacionado con la aplicación de la pena de muerte.

^l Este artículo señala: "La Corte someterá a la consideración de la Asamblea General de la Organización en cada período ordinario de sesiones un informe sobre su labor en el año anterior. De manera especial y con las recomendaciones pertinentes, señalará los casos en que un Estado no haya dado cumplimiento a sus fallos".

42 Corte INTERAmericana de Derechos humanos. Informe Anual 2003. San José: Corte Interamericana de Derechos Humanos, 2004, p. 68. 
Destaca, en esta sentencia, que la Corte haya resuelto que la legislación relativa a la pena de muerte del Estado demandado era incompatible con la Convención, pues establecía de modo obligatorio esta sanción para el caso de los delitos de homicidio, sin dejar a los jueces la posibilidad de evaluar cada caso concreto. Sin analizar un caso específico, sino únicamente la norma, la Corte concluyó que esta era contraria a la prohibición de privaciones arbitrarias de la vida prevista en la Convención (artículo 4.1) y a la exigencia de aplicar la pena capital solo en el caso de los delitos más graves (artículo 4.2). La sola vigencia de esa norma atentaba también contra la obligación del Estado de adoptar medidas a favor de los derechos fundamentales (artículo 2). Teniendo en cuenta estas consideraciones, ordenó que el Estado se abstuviese de aplicar esta legislación sobre pena de muerte y la modifique según los lineamientos señalados en la sentencia, a fin de que sea compatible con la Convención.

Sin embargo, esta importante decisión de la Corte no ha sido aún cumplida por el Estado demandado, sin que existan posibilidades de adoptar alguna medida de coerción ante tal situación, pues no se ha previsto ninguna en la Convención Americana. Sin lugar a dudas, se trata una de las deficiencias más graves del sistema, que aquí se manifiesta de modo contundente. 